\title{
Controlling infection in a district general hospital
}

\author{
PAUL NOONE ${ }^{1}$ AND M. S. SHAFI \\ From the Bacteriology Department, Central Middlesex Hospital, London
}

SYNOPSIS The way in which hospital-acquired infection has been brought under control over a three-year period in a district general hospital is described.

The main success has been achieved in reducing sepsis caused by Staph. aureus, especially methicillin-resistant strains, and Pseudomonas aeruginosa.

These reductions were achieved in spite of inadequate ward isolation and operating theatre facilities, and before there was any marked change in patterns of prescribing antibiotics.

Our experiences indicate the significant improvements that can be made in controlling nosocomial sepsis even without structural or other major alterations in a hospital, providing that the problem is fully appreciated and the infection control team are concerned enough to act vigorously in influencing their clinical colleagues.

Hospital infection has been recognized as a serious problem for many years. In the 1940 s sulphonamides and penicillin helped to bring under control sepsis caused by Strep. pyogenes and then in the 50s epidemic antibiotic-resistant Staph. aureus became a major problem causing postoperative wound sepsis, septicaemia, endocarditis, and enterocolitis with considerable mortality, morbidity, and economic loss (Williams, Blowers, Garrod, and Shooter, 1966).

The introduction of penicillinase-resistant penicillins, methicillin, and its successors; the use of antiseptics such as hexachlorophane; and the development of the hospital infection control team of microbiologists, nurses, and technical staff has led to Staph. aureus sepsis being brought under control in many hospitals. Later, reports of sepsis caused by Staph. aureus resistant to these penicillinase-resistant penicillins caused some alarm (Parker and Hewitt, 1970; Jensen and Lassen,' 1969) and a menacing situation has developed in some hospitals from the proliferation of such strains (Hale and Selkon, 1970). As early as 1965 Colley, McNicol, and Bracken described 73 isolations of such organisms, 51 associated with sepsis, in this hospital.

Pseudomonas sepsis also has been a serious problem-particularly in relation to the urinary and respiratory tracts.

In this study, we describe the way in which sepsis caused by Staph. aureus, especially methicillin-

\footnotetext{
${ }^{1}$ Present address: Bacteriology Department, Royal Free Hospital, London WC1X 8LF.

Received for publication 8 December 1972.
}

resistant strains, and Pseudomonas aeruginosa was brought under control in the period 1968-1971.

\section{Materials and Methods}

There were three main sources of specimens submitted to the laboratory from inpatients for bacteriological investigation.

Most specimens were collected on the clinicians' initiative. After the appointment of a control of infection nursing officer in December 1968, increasing numbers of specimens were collected on her initiative, especially from patients with postoperative wound sepsis, and from patients, staff, and environment when screening for particular pathogens during epidemics of infection or for any other reason.

The medical staff of the Microbiology Laboratory provide an advisory service for clinicians. This involves visiting patients on wards when invited to do so and when information received in the laboratory indicates that this may be useful. Specimens are often collected on these occasions.

In this manner close surveillance of hospital patients for infection was achieved during 1969, 1970, and 1971.

Laboratory methods are continuously reviewed and improved. In the later part of 1968 and the early part of 1969 considerable changes were made. This had special significance in the detection of methicillinresistant Staph. aureus. In 1968 (and previously) cloxacillin and methicillin resistance were detected by using cloxacillin discs on sensitivity test agar 


\begin{tabular}{|c|c|c|c|}
\hline \multirow[t]{2}{*}{ Six-month Periods } & \multicolumn{3}{|l|}{ Isolations of Staph. aureus } \\
\hline & $\begin{array}{l}\text { Total Associated with Sepsis in } \\
\text { Central Middlesex Hospital }\end{array}$ & $\begin{array}{l}\text { Resistant to Two or More } \\
\text { Antibiotics }\end{array}$ & Methicillin-resistant \\
\hline $\begin{array}{l}\text { Jan.-June } 1968 \\
\text { July-Dec. } 1968 \\
\text { Jan.-June } 1969 \\
\text { July-Dec. } 1969 \\
\text { Jan.-June } 1970 \\
\text { July-Dec. } 1970 \\
\text { Jan.-June } 1971 \\
\text { July-Dec. } 1971\end{array}$ & $\begin{array}{l}433 \\
406 \\
411 \\
404 \\
396 \\
306 \\
238 \\
247\end{array}$ & $\begin{array}{l}224(52 \%) \\
183(45 \%) \\
174(42 \%) \\
148(36 \%) \\
124(31 \%) \\
72(23.5 \%) \\
59(24 \cdot 8 \%) \\
52(21 \%)\end{array}$ & $\begin{array}{l}20(4.6 \%) \\
40(9.8 \%) \\
66(16 \%) \\
59(14.6 \%) \\
37(9 \%) \\
8(2.6 \%) \\
2(0.8 \%) \\
1(0.4 \%)\end{array}$ \\
\hline
\end{tabular}

Table I Methicillin-resistant and other multiple antibiotic-resistant strains as a percentage of total strains of Staph. aureus causing sepsis

inoculated with the test strain and incubated at $37^{\circ} \mathrm{C}$ overnight. From January 1969, for a period of three months, all strains of Staph. aureus from inpatients were sent to the Cross-Infection Reference Laboratory, Colindale, for phage typing and for confirmation of methicillin resistance.

From March 1969, methicillin resistance was detected by the use of methicillin discs $(10 \mu \mathrm{g})$ on
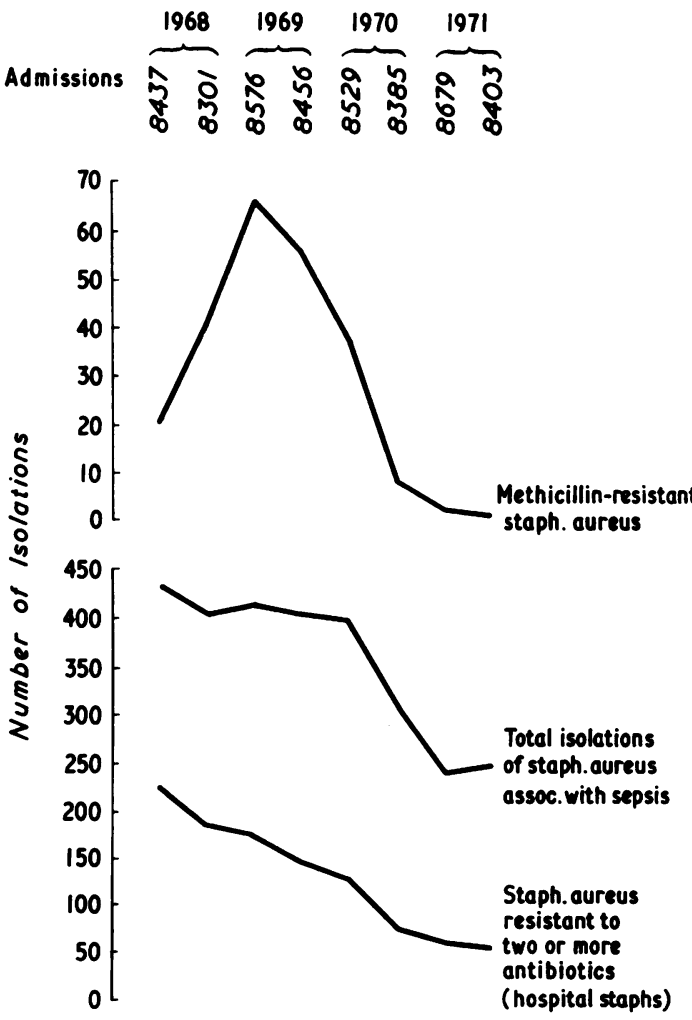

Fig. 1 Total isolations of Staphylococcus aureus associated with sepsis.
DST agar (Oxoid) inoculated with the test strain and incubated overnight at $30^{\circ} \mathrm{C}$. Strains growing to within $1 \mathrm{~mm}$ of the disc were reported as 'resistant to cloxacillin' after comparison with a control plate set up simultaneously and inoculated with the Oxford strain of Staph. aureus (NCTC 6571) (Parker and Hewitt, 1970).

The minimum inhibitory concentration (MIC) of methicillin for resistant strains was $12.5 \mu \mathrm{g} / \mathrm{ml}$ or greater. Routine phage typing of all isolations was discontinued but methicillin-resistant and all epidemiologically relevant strains were sent to the CrossInfection Reference Laboratory for phage typing where methicillin resistance was invariably confirmed.

Selected strains of Pseudomonas aeruginosa were also sent to the Cross-Infection Reference Laboratory for typing.

All isolations of pathogenic bacteria were recorded daily in a register and notes made of any association with sepsis together with details of the patient, the site of infection, and the ward. Each fresh isolation from any site, associated with sepsis, caused by a single strain of an organism, was counted as a new case of sepsis. Repeated isolations of the same strain from the site were excluded from the calculations of sepsis rates; only cases of sepsis were counted and isolations of potential pathogens colonizing a patient without causing sepsis were excluded. The presence of sepsis was indicated by the production of pus, as recognized by the infection control team and/or clinicians; or the isolation of organisms from sites which should be sterile, eg, blood, with associated symptoms and signs of disease.

\section{Results}

STAPH. AUREUS

Total isolations of Staph. aureus associated with sepsis are summarized in Fig. 1 and Table I. The total number of patients admitted each year has remained almost constant. There has been a con- 
Fig. 2 Isolations of methicillin-resistant Staphylococcus aureus (epidemics associated with them).

siderable fall in the number of isolations of Staph. aureus associated with sepsis, this decrease being particularly striking with respect to strains resistant to two or more antibiotics. The total number of methicillin-resistant strains isolated showed an increase during the year 1969. This was attributed to

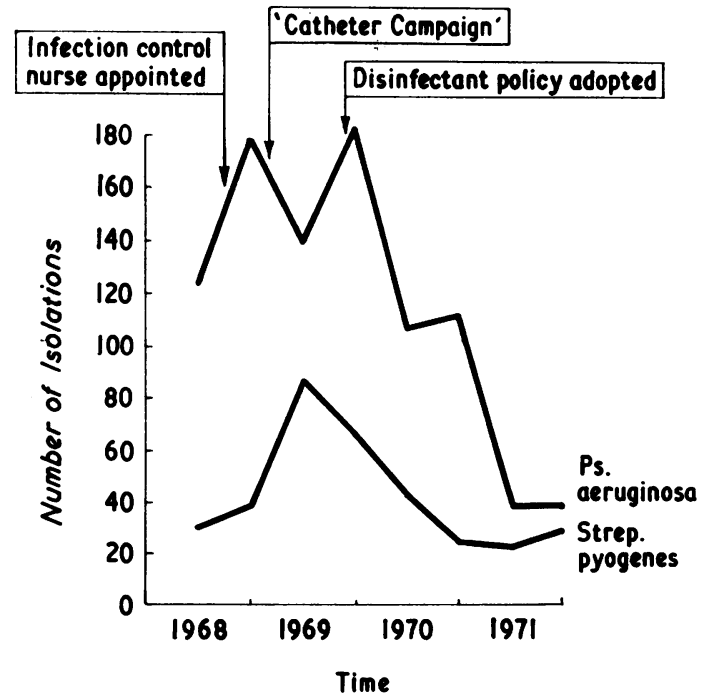

Fig. 3 Isolations of Pseudomonas aeruginosa and Streptococcus pyogenes associated with sepsis. the introduction of improved methods of detectin methicillin resistance which coincided with a mucs closer surveillance programme. Figure 2 shows totaf isolations of methicillin-resistant Staph. aureus and also indicates when epidemics occurred.

PSEUDOMONAS AERUGINOSA

Figure 3 shows the number of isolations every sixmonth period from 1968 to 1971. Most of the infection until the first half of 1970 was attributable to catheterization and the use of equipment such as cystoscopes and ventilators disinfected by inadequate methods, eg, dry formalin cabinets and containers. Cases of serious sepsis associated with this organism included patients with septicaemia: one in 1968, three in 1969, four in 1970 (two fatal), and one in 1971. Isolations of Pseudomonas spp. from specimens of antral washouts were made on several occasions. Investigations revealed that tap water had been used for these washouts (Lancet, 1972).

One outbreak of sepsis caused by Pseudomonas aeruginosa took place in the maternity unit. The source of this outbreak was contaminated disinfectant. Pseudomonas was first isolated from the infected eye of a premature baby. There followed three cases of deep wound infection five to seven days after operation in mothers who had undergone lower segment caesarian section in the same operating theatre; one of them was the mother of the infected 
infant. The three patients came from different wards and were under the care of different surgical teams. On investigation in the theatre, a heavy growth of Pseudomonas aeruginosa was obtained from a swab dipped into a glass dish containing $0.5 \%$ aqueous chlorhexidine solution in which suture needles were kept. The needles were supplied in sterile packets by the manufacturers but were kept before use in chlorhexidine. The organism isolated from the three mothers and from the chlorhexidine belonged to the same phage and serological type (type 10).

\section{Factors Contributing to Reduction in Infection}

Records show also (Fig. 3) that there has been a marked reduction in infections with Pseudomonas aeruginosa during the period under review. There are several factors which have contributed to this.

\section{LIMITING CATHETERIZATION}

Early in 1969 an energetic 'campaign' was conducted to limit catheterization of patients because of the nearly universal subsequent infection of these patients with coliforms and Pseudomonas aeruginosa. Catheterization simply to prevent bed wetting in elderly patients was discouraged and all catheterization could be carried out only following a medical decision and not on the initiative of nurses.

\section{ABANDONING FORMALIN CABINETS}

The use of dry formalin vapour cabinets in theatres for disinfecting cystoscopes was discontinued and pasteurization carried out instead, using water at $75^{\circ} \mathrm{C}$ (Francis, 1961).

\section{CONTROLLING DISINFECTANT USAGE}

In late 1969 a complete review of the hospital use of disinfectants was undertaken by the infection control committee with expert advice from the Disinfection Reference Laboratory, Colindale. As a result the inappropriate use of some disinfectants and antiseptics, especially the combination of chorhexidine and cetrimide, was greatly reduced. It involved such changes as no longer storing nail brushes in this antiseptic mixture and ending its routine addition to cleaning water which incidentally contained an incompatible detergent and was applied to the floor with a 'string mop'.

There is evidence to suggest that the inappropriate use of disinfectants encourages the proliferation of Pseudomonas aeruginosa in hospitals (Kresky, 1964; Bassett, 1971 ; Lowbury, 1971 ; Whitby and Rampling, 1972; Cooke, Shooter, O'Farrell, and Martin, 1970; Lancet, 1972) and the more rational use of these agents in the Central Middlesex Hospital has been associated with a reduction in the incidence of sepsis associated with this organism.

\section{EFFICIENT DISINFECTION OF RESPIRATORY} EQUIPMENT

Humidifiers and respirators present problems as regards their effective disinfection after use by patients with Pseudomonas and other infections of the respiratory tract. The less intensive use of such apparatus, coupled with more thorough cleaning and treatment with water-saturated formalin vapour in an enclosed polythene chamber, led to disinfection as monitored by the laboratory.

\section{Discussion}

During 1970 and 1971, the number of isolations of Staph. aureus, and specially those resistant to methicillin, was dramatically reduced and this can be attributed to the control measures that were taken.

The increase in isolation of these organisms in $1969 / 70$ is attributable to improved methods of detection of methicillin resistance, although reports of sepsis caused by these strains had been reported from Central Middlesex Hospital up to six years earlier (Harding, 1963). It is probable that the true incidence of sepsis by these strains had been underestimated for several years before 1969. That methicillin resistance is of clinical significance and not a mere laboratory finding is strikingly underlined by the fact that at least five patients developed sepsis from methicillin-resistant strains in the period under review while receiving $500 \mathrm{mg}$ cloxacillin six hourly (Noone and Griffiths, 1971). The advent of the infection control nursing officer also helped in the fuller surveillance and investigation of sepsis and its causes and no doubt resulted in a greater awareness of the problems involved.

Figure 2 shows the consumption of penicillins in this hospital. Methicillin-resistant staphylococci have been found in large numbers in populations where this antibiotic has not been in use (Cetin and Aug, 1962; Borowski, Kamienski, and Rutecka, 1964; Pal and Ghosh, 1964) but it has been suggested that its isolation is related to penicillin usage. Ampicillin consumption has steadily increased in this hospital from 1969 to 1971 while both cloxacillin and benzylpenicillin consumption increased in 1970. Some attempt has been made to limit the use of certain antibiotics, including cephalosporins, by liaison between pharmacists and microbiologists, eg, on being informed of a new prescription for cephalosporins, the bacteriologist would contact the clinician concerned and discuss the problem, dissuading the clinician from using the drug unless it was agreed to be essential. It is worth noting that control of 
staphylococcal and pseudomonas infection seemed to be achieved in spite of the increased consumption of antibiotics in 1970.

We believe that three particular features played an important part in our attempts to control infection and staphylococcal sepsis in particular.

\section{RECOGNITION OF PROBLEMS}

The scale of the problem had to be recognized and methods for detecting and monitoring sepsis developed. This was achieved through close surveillance of wards, operating theatres, service departments, clinical and nursing practice, and careful control of the provision of sterile and disinfected equipment. There was also careful recording and collation of bacteriological information. This became possible only through the conscientious working of the infection control team of medical, nursing, and technical staff liaising closely with each other and with the ward and other hospital staff.

\section{PREVENTING SPREAD OF INFECTION}

Patients with sepsis or those carrying epidemic and/or multiple antibiotic-resistant strains were isolated by transference to the Infectious Diseases Hospital or more often by being barrier nursed in the single bed cubicle on each ward. The inappropriate use of systemic antimicrobial chemotherapy, eg, nonspecific prophylaxis before 'clean' surgery was discouraged while $2 \%$ hexachlorophane was used both as a soap and a cream for treating superficial infection. Nasal carriers were also treated with $2 \%$ hexachlorophane cream applied to the anterior nares combined with the concurrent use of $2 \%$ hexachlorophane-containing soap (Noone, Griffiths, and Taylor, 1970).

As in many other hospitals of similar age and design, isolation facilities are grossly inadequate. The wards are mostly of the Nightingale type for 25 to 30 patients with one single bed cubicle and one two-bed cubicle only, usually without separate wash hand basins. With the cooperation of the clinical staff, some patients were transferred to the Group Infectious Diseases Hospital for isolation but this was often difficult because clinicians claimed that the prior needs of the patient for specialist treatment could not be met in the isolation hospital, especially in respect of surgical patients.

When epidemics could not be prevented by the above measures, wards were closed to new admissions, emptied, and cleaned (Noone and Griffiths, 1971), while staff and patients were investigated for carriage of the epidemic organisms. Only after carriage of epidemic strains of organisms had been eliminated were staff allowed to return to duty. On \& few occasions patients carrying epidemic strains we allowed back into cleaned wards but only into sing cubicles with barrier nursing.

Six wards were closed during the period 1968 to

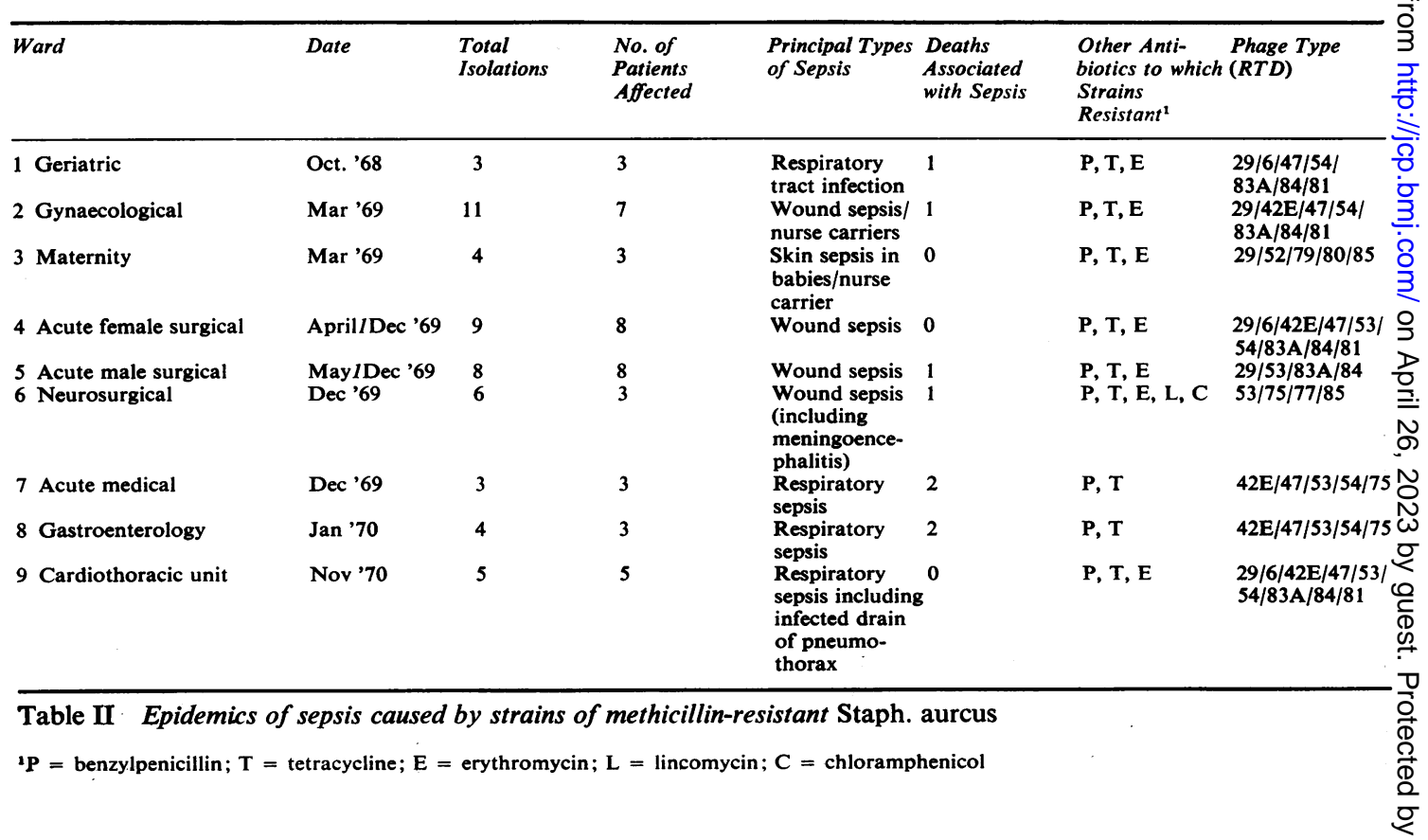


1970 and in each case sepsis caused by an epidemic strain of methicillin-resistant Staph. aureus was ended (see Fig. 2 and Table II).

\section{EDUCATION OF STAFF}

Prevention of outbreaks of sepsis was attempted not merely by the previous two measures of improved detection and interruption of transmission, including the elimination of the carriage of potential pathogens, but also by education, ie, by increasing the awareness of hospital infection and the ways in which it can be prevented by proper attention to surgical, nursing, and other techniques amongst medical, nursing, and other staff.

In 1971, Staph. aureus sepsis came under control and there were only three instances of infection with methicillin-resistant strains, including an isolation from a cholecystectomy wound of a patient. It was discovered that nursing practice in this ward was to pool all the pieces of gauze and cotton wool swabs left over from individual dressing packs with the intention of re-using them without further sterilization. A similar strain of Staph. aureus was isolated from dressing gauze in the same ward.

Our experiences at Central Middlesex Hospital indicate quite clearly what can be achieved in terms of reducing sepsis in a district general hospital with poor isolation facilities and without an antibiotic policy, providing bacteriologists and infection control nurses develop a close working relationship with the clinical and ward staff.

We would like to thank Dr C. E. D. Taylor, Dr R. E. M. Thompson, and Mrs R. J. Taylor for their help and advice in the preparation of this paper. We would also like to thank Mr M. Coles, the laboratory staff, and all the staff of Central Middlesex Hospital;
Dr M. T. Parker and the staff of the Cross Infection Reference Laboratory at Colindale; and Mrs I. G. Maurer of the Disinfection Reference Laboratory for cheir invaluable help.

\section{References}

Bassett, D. J. (1971). Causes and prevention of sepsis due to gramnegative bacteria: common source outbreaks. Proc. roy. Soc. Med., 64, 980-985.

Borowski, J., Kamieński, K., and Rutecka, I. (1964). Methicillinresistant staphylococci. Brit. med.J., 1, 983.

Cetin, E. T., and Ang, O. (1962). Staphylococci resistant to methicillin (celbenin). Brit. med. J., 2, 51-52.

Colley, E. W., McNicol, M. W., and Bracken, P. M. (1965). Methicillinresistant staphylococci in a general hospital. Lancet, 1, 595-597.

Cooke, E. M., Shooter, R. A., O'Farrell, S. M., and Martin, D. R. (1970). Faecal carriage of Pseudomonas aeruginosa by newborn babies. Lancet, 2, 1045-1946.

Francis, A. E. (1961). The use of a pasteurising water bath for disinfection of cystoscopes. $J$. Urol., 86, 679-682.

Hale, J. H., and Selkon, J. B. (1970). Multiply resistant staphylococci, Lancet, 2, 528-529.

Harding, J. W. (1963). Infections due to methicillin-resistant strains of Staphylococcus pyogenes. J. clin. Path., 16, 268-270.

Jensen, K., and Lassen, H. C. A. (1969). Combined treatment with antibacterial chemotherapeutic agents in staphylococcal infections. Quart. J. Med., n.s., 38, 81-106.

Kresky, B. (1964). Control of gram-negative bacilli in a hospital nursery. Amer. J. Dis. Childh., 107, 363-369.

Lancet (1972). Annotation. Disinfection and gram-negative bacteria. Lancet, 1, 26.

Lowbury, E. J. L. (1971). Control of infection with gram-negative bacteria in patients at special risk. Proc. roy. Soc. Med., 64, 986-988.

Noone, P., and Griffiths, R. J. (1971). The effect on sepsis rates of closing and cleaning hospital wards. J. clin. Path., 24, 721-725.

Noone, P., Griffiths, R. J., and Taylor, C. E. D. (1970). Hexachlorophane for treating carriers of Staphylococcus aureus. Lancet, 1, 1202-1203.

Pal, S. C., and Ray, B. G. (1964). Methicillin-resistant staphylococci. $J$. Indian med. Ass., 42, 512-517.

Parker, M. T., and Hewitt, J. H. (1970). Methicillin resistance in Staphylococcus aureus. Lancet, 1, 800-804.

Whitby, J. L., and Rampling, A. (1972). Pseudomonas aeruginosa contamination in domestic and hospital environments. Lancet, 1, 15-17.

Williams, R. E. O., Blowers, R., Garrod, L. P., and Shooter, R. A. (1966). Hospital Infection: Causes and Prevention, 2nd ed. ch. 3 and 6. Lloyd-Luke. 